\title{
Aerospace Supply Chains as Evolutionary Networks of Activities: Innovation via Risk-Sharing Partnerships
}

\author{
Christen Rose-Anderssen, James S. Baldwin, \\ Keith Ridgway, Peter M. Allen and Liz Varga
}

\begin{abstract}
In the aerospace industry competitive advantage is searched through product innovation. This paper sets out to explore the effects that relationship development in the commercial aerospace supply chains have on innovation and competitive advantage. A perspective of supply chains as complex activity networks is used for data analysis based on in-depth interviews in a global setting. Applying these concepts of supply chains as the interaction of multiple work activities assists in comprehending the forces of change. The processes of change are characterized by expansive learning processes of creating instruments for initializing, developing and sustaining these relationships. These processes take place in a terrain of complex power exercises. The long-term effects are totally dependent on nurturing the relationships. The findings may be useful to practitioners in understanding how implementation of successful supply chain changes may come about. It promotes risk-sharing partnerships as instruments for innovation. The paper provides evidence of changing relationships in commercial aerospace supply chains.
\end{abstract}

\section{Introduction}

In response to fiercer competition in the global marketplace, there has been a call for innovative solutions in terms of products, technologies and practices at the same time as reducing lead-time and costs (Rose-Anderssen et al., 2005; Goffin et al., 2006). The obvious approach to reduce lead time and costs has been to adopt the lean practices of the automotive industries. The key principles of lean practices are open dependencies between business partners, just-in-time deliveries and no wastage of resources and materials (Womack et al., 1990). Creating innovative solutions, however, requires going beyond the improvement of adopting practices used within other industries and by competitors. Competitive advantage can be enhanced through introducing radically new products into the market. Veryzer (1998) refers to these new products as discontinuous innovations, where the products have been designed beyond customers' imagination. In that sense creative performance and innovation can be positively influenced by what Kratzer et al. (2006) refer to as team polarity. Team polarity is defined as the difference in opinions and perspectives among members of innovative teams. In this paper, Kratzer et al.'s polarity is referred to as diversity.

The case study presented has its focus on the global competition in the market for large commercial aircraft. Risk-sharing partnerships are used as instruments for enhancing innovation and competitive advantage for a new aircraft model; the tenet being that risk-sharing partnerships allows for exploratory processes and financial strength that go beyond the limited creative capacity of a firm working alone. The paper then presents supply chains as evolutionary networks of multiple work activities. These work activities are discussed in terms of the evolutionary transformation of relationships at boundaries. Within this discussion a model of the instrumentality of relationships as complex evolutionary processes is 
introduced. Following this, a method of data collection is proposed and justified. The case is then discussed within the framework of the model in the specific context of one airframe manufacturer and its suppliers.

A combination of an activity theoretical approach and complex systems thinking is applied for analysing these processes of change. Work activities are characterized by the multi-voiced interaction created within them, and their potential for expansive transformation (Engeström, 2001). In this communicative interaction, the diversity of opinions and perspectives create contradictions that play a central role as sources of change and development. Contradictions are historically accumulated tensions within and between activity networks (Engeström, 2001). In these activities there are continuous processes for creation of new instruments for change (Engeström, 1987).

\section{Risk-Sharing Partnerships as Instruments for Innovation}

A supply chain can be defined as the integration of the flow of information and materials between customers, manufacturers and suppliers (Samaranayake, 2005). There are different aerospace supply chain forms. These are characterized by changing practices in the evolutionary adaptation to market realities and to proactive responses to increased competition (Rose-Anderssen et al., 2009). The adaptation can be exemplified in lean practices, where complex networks of suppliers and customers are closely integrated into long-term relationships for reducing costs and ensuring high quality (Cagliano et al., 2004). Risk-sharing partnerships, on the other hand, are proactive responses to increased competition.

Traditionally airframe manufacturers handled most of the risk associated with innovation, development and production (Williams et al., 2002). Risk-sharing partnerships, however, spread this risk at the same time as influence and revenue is shared between the partners. Risk-sharing partnerships used as instruments for enhancing creative capacity is based on the intention of integrating a diverse division of labour and expertise held by each partner company. It is the synergetic effects caused by collaboration on diversity of perspectives through constructive dialogue while creating a shared voice and vision (John-Steiner, 2000) that is sought when bringing firms into collective partnerships. From the point of division of expertise, Gemünden et al. (2007) have studied the roles of innovators in highly innovative ventures. In this so-called German approach, four types of promoters of innovation are identified. First, there is the power promoter who has the necessary hierarchical power to drive a project. Second, there is the expert promoter who has the specific technical knowledge for the innovation process. Third, the process promoter has the expertise of organizational know-how and network building. Fourth, the relationship promoter has the strong personal ties outside the organization. Although this paper is not about individuals in the single firm, our findings regarding individual firms engaged in radical innovations in aircraft production fit the role models of the German approach (Table 1). As will be seen in this paper, the instruments used in these roles are important for large-scale commercial aircraft innovation.

Pritchard and MacPherson $(2004,2007)$ are concerned about the substantial technology transfer from the prime contractor to globally- located risk-sharing partners and the loss of jobs among skilled workers and designers in the Western commercial aircraft sector. 
Table 1. Innovation Process

\begin{tabular}{|c|c|c|}
\hline Role & $\begin{array}{l}\text { The German } \\
\text { single firm } \\
\text { approach }\end{array}$ & The aerospace supply chain approach \\
\hline 1 & Power promoter & Airframe manufacturer \\
\hline 2 & Expert promoter & Expert risk-sharing partners \\
\hline 3 & Process promoter & $\begin{array}{l}\text { Large scale integrators; risk-sharing } \\
\text { partners }\end{array}$ \\
\hline 4 & $\begin{array}{l}\text { Relationship } \\
\text { promoter }\end{array}$ & $\begin{array}{l}\text { Airframe manufacturer towards airlines and } \\
\text { risk-sharing partners } \\
\text { Risk-sharing partners towards suppliers, their } \\
\text { local governments and airlines }\end{array}$ \\
\hline
\end{tabular}

Nonetheless, Romano (2003) argues that supply network partners, in realizing their interdependencies, seek to improve the competitiveness of the network as a whole. Complex global networks of one airframe manufacturer and its suppliers are formed to reduce financial, technological and market access barriers (Esposito, 2004). The reality shift from the traditional local subcontractor base is also enforced by the fact that there is a growth demand in the key emerging markets (Lefebvre \& Lefebvre, 1998).

Changing the form of relationship from one type to another is not only a matter of choice but also a matter of capacity to do so. The realistic point of departure here is to assess the reality of power regimes within the supply network and adapt and work according to these (Cox, 2004). The lack of general appropriateness of supplier development models and supply chain managed models is that they both become effective in situations of buyer dominance and interdependence only. Risk-sharing partnerships emphasize the importance of the latter. In this regime of relationships, technological innovation depends particularly on the co-ordination and integration activities ensuring durable relationships between customers and suppliers (Lefebvre \& Lefebvre, 1998).

\section{Activity Networks and Boundary Crossing}

Aerospace supply chains are complex systems of power relationships. Complex systems thinking, pioneered in the natural sciences by I. Prigogine and his colleagues in the 1970s, is attaining increasing recognition for understanding change, adaptation and evolutionary processes within social and industrial settings. Cultural-historical Activity Theory was founded by L. Vygotsky, A.N. Leont'ev and A.R. Luria in SovietRussia in the 1920-1930s. This theory is a philosophical framework for studying different forms of human work practices and their transformation.

The theoretical concepts in this section will be applied to the evolutionary framework of Figure 1. 


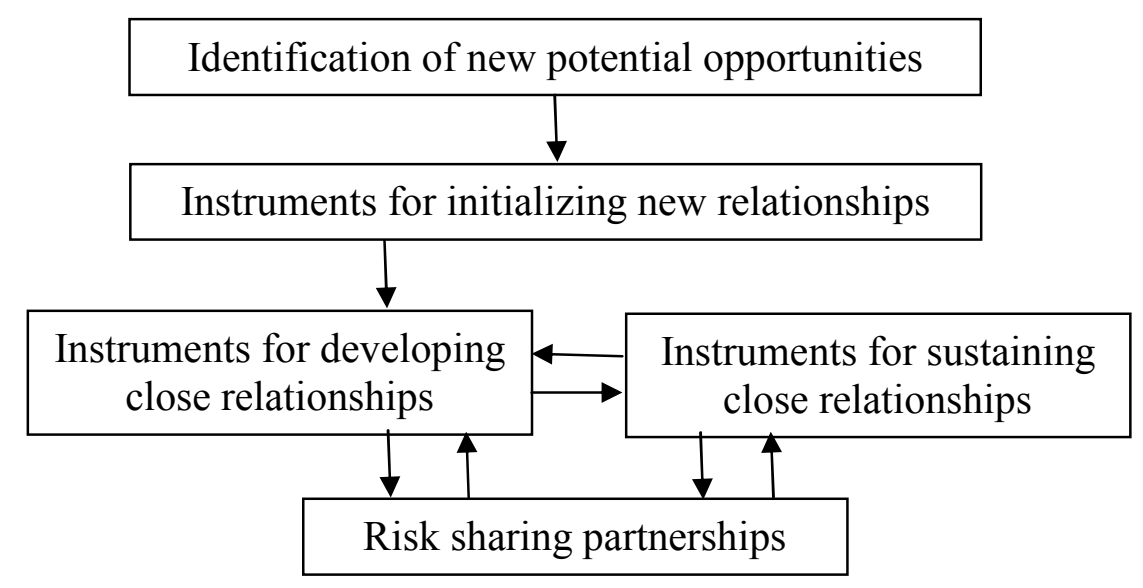

Figure 1. Instrumentality of Relationships as Complex Evolutionary Processes

A work activity is a complex network of individuals and their human artefacts (RoseAnderssen \& Allen, 2008). As such it is a developmental process connecting the individual and the social levels through their human artefacts and their object orientation. In these complex networks the physical reality is governed by the complex set of invisible effects of individuals interacting by using a diversity of opinions and experiences (Rose-Anderssen et al., 2005). The network as a whole may therefore potentially adapt and respond to the environment in multiple and unpredictable ways (Allen, 2001a). It is the excess diversity that fuels adaptation, exploration and change. Innovation is therefore restricted when diversity is reduced and standardization is increased (McCarthy, 2004). As an activity is already a network, the supply chain becomes a complex network of multiple work activities. Here individuals interact within and across boundaries between companies. The human artefacts are similarly used within and across company boundaries.

\section{The Evolution of a Work Activity and the Significance of History}

The elements of the activity are represented by the individual subjects of consideration, their activity community, the object and the mediating human artefacts. There are three mediating artefacts. The instruments mediate between the individual and the object. The social rules mediate between the individual and the activity community. And the division of labour and expertise mediates between the community and the object. It is important to make a distinction between object and objectives. Objectives are rigidly independent of individual conceptions, personal bias, thoughts and feelings. An object, however, is the emerging vision that integrates the elements of the activity (Figure 2).

Qualitative change can occur when there are disturbances between the elements. That is, change occurs at moments of instability when some new aspects or elements grow in the system, restructure it, and invade new dimensions. Thus new properties of the elements continually emerge (Rose-Anderssen et al., 2005), making the outcome unpredictable in detail. The emerging changes to supply chains beyond individual human control must therefore always be of concern through collective efforts. Under these dynamic circumstances, the relationships between the elements are therefore in continual processes of modification. And they take multiple and diverse forms within the time of the activity (Foucault, 1972). In other words, as people try to change and develop an activity, they are themselves changed by their adaptation to these changes.

The object is central for integrating individual action into a collective activity. The point of departure is the identification of a problem or an opportunity. In the case and results section, the airframe manufacturer identifies a potential opportunity to gain a competitive advantage through closer integration of key suppliers. This is the initiation of an object formation process with the basis in risk- sharing partnerships. 
Instruments: Concepts, language,

technologies, strategies

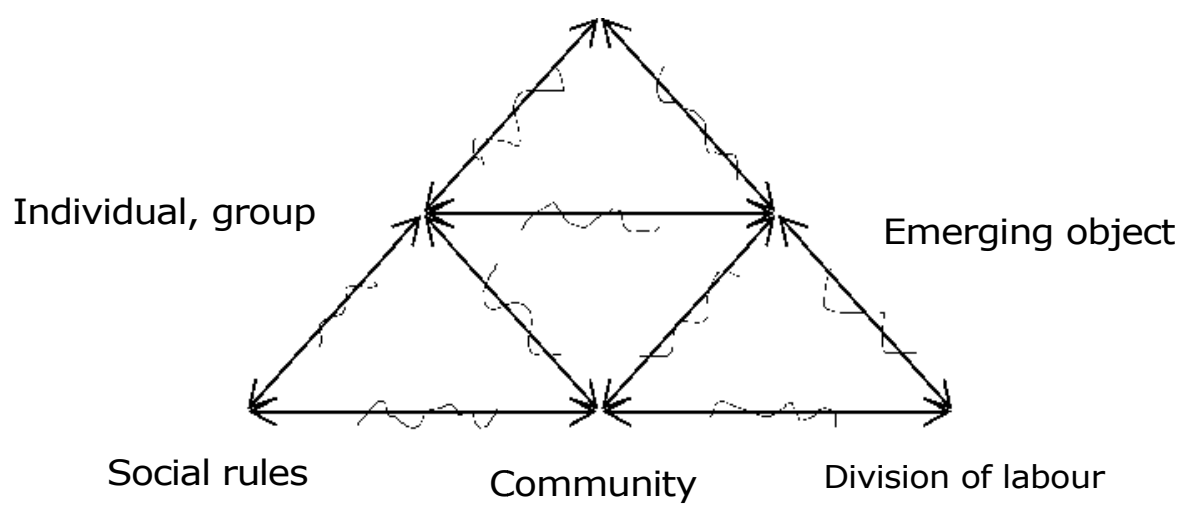

Figure 2. Complex Activity Network (Engeström, 1987)

The Mediating Artefacts of Work Activities

Vygotsky (1978) argues that an instrument's function is to serve as the individuals' influence on the object of the activity. The instruments are therefore the tools and signs individuals are jointly applying in developing the object (Kerosuo \& Engeström, 2003). Essential signs are the languages individuals use to co-ordinate their actions with others (Blackler, 1993).

Burns and Flam (1987) argue that social rules have a collective purpose. In that sense they are means for co-ordination within an activity for meeting mutually desirable ends. They serve as means for producing clearer communication and thereby reduce social uncertainty. Successful coordination of supply chains are dependent on some shared rules of comprehension of how to interact in the supply chain. However, sharing social rules does not necessarily mean the same as consensus. The core set of the organizing principles or rules are the contradictions and they are also outcomes of unintended actions.

The division of labour in the supply chain comes about as a mutual need for bringing together a diversity of experience and ability with an intention to use this excess knowledge capacity to develop a new object that can give directions to innovative solutions. There is a choice of instruments for initializing new relationships within the network of airframe manufacturer and its first-tier suppliers. The most obvious choice is language. The initiative would normally start off by getting into a dialogue on mutual needs to see how these could be shared, and then reaching some consensus on the form of the new relationships.

\section{The Complex Dynamics of Work Activities}

The Object Formation Process and Instruments for Change

Central to activities is the object formation process. In that respect Hasu and Engeström (2000) make the following distinction between the goals individuals have for their actions, and the collective purpose and direction the object gives to an activity. The object becomes the visual target or focus collectively being created by the community of a particular activity. Because of individuals' different interpretation of the object, it is continuously subject to changing influences. The dynamics of the influences sustain the object's evolutionary capacity. As an emerging collective property, the object becomes clearer and more meaningful (Lektorsky, 1984) as people co- explore their work activity. 
An object can occupy two different roles. First, it functions as an object and then it may function as an instrument (Foot, 2002). This paper explores the instruments used for the object of developing relationships in supply chains. Simultaneously the developing relationships are used for enhancing innovation.

\section{Knowledge and Routines versus Expansive Learning}

Miettinen and Virkunnen (2005) argue that notions of routine and rule-governed action do not explain the emergence of new practices. Traditionally, routines have been conceptualized as carriers of regular and predictable practices. From that perspective routines are seen as carriers of an organization's skills and knowledge. In supply chains this becomes more difficult as the chain is a meeting place of several companies' different routines.

Going beyond the limitations of routines in a rapidly changing environment, communities with the ability to learn will prevail over communities with optimal, but fixed behaviour (Allen, 2001b). In that sense Blackler (1995) argues that the notion of knowledge should rather be seen as a dynamic process of social construction, the knowing in doing. That is, at moments of instability, during which knowledge is transformed, qualitative and structural change can be created (Rose-Anderssen et al., 2005). In other words, it is the transformation of knowledge in order to adapt the supply chain to the future that is interesting. This means releasing the creative capacity within the supply chain into these unstable situations. Here, individuals start questioning present practices and suggest new models of practice. When these challenged models descend to the practical level of implementation, and are tested out in practice, this collective movement has become an expansive learning process (Engeström, 1987). These expansive learning processes, Engeström argues, should be viewed as partially destructive rejection of old perspectives and practices. As collective practices, collaboration between firms on developing radically new products also becomes practice in developing close relationships. The learning in doing therefore transforms both knowledge and relationships.

\section{Dilemma Situations and Boundaries}

Dilemma situations occur at boundaries (Kerosuo \& Engeström, 2003). A boundary is crossed as an individual tries out new instruments in interaction with another individual in order to inquire or negotiate a common object for creation of alternative practices. At the social level essential dilemmas cannot be resolved through individual actions alone. Here it is the collective creation of new instruments that resolves the dilemma. In that sense, evolving inner contradictions are the chief sources of movement and change in the activity network. For the supply chain as such the inner contradictions are, as Kratzer et al. (2006) argue, the potential for creative performance.

In supply chains, boundaries are therefore experienced when old practices do not work. This may occur when involving suppliers from low cost economy (LCE) countries or when trying to search for more innovative solutions.

Developing close relationships are collective processes. These processes are characterized by dismantling those old routines that would inhibit relationships across company boundaries. The instrument risk-sharing partnerships can be used as a crowbar for negotiating how to collectively proceed. And that is a continuous dialogical process of questioning present practices and how to change these.

\section{Power, Distance, Trust and Relationships}

Power differences create boundaries. In that sense traditional supply chain forms of buyer dominance create boundaries. Power is really shifting from action to action (Engeström, 2000), and it is therefore shifting from actor to actor (Foucault, 1980; Giddens, 1982). Therefore the ability of any individual to construct reality is 
completely dependent on their place in the activity process, mediated by the division of labour (Engeström, 2000).

Power and distance issues are a challenge to master in human relationships. Scollon and Scollon (1983) argue that the way we speak or the way our discourse systems work are governed by both the way individuals or groups value or assume a relationship when an imposition is put upon them in terms of power relationships, and the distance between self and the other (in terms of closeness of relationship). In that respect, meaningful interactive relationships between people are facilitated by trust as it produces mutual expectations (Bachmann, 2003). Mutual expectations are developed through the object formation process. Trust is associated with the risk of things going wrong (Nooteboom \& Six, 2003). However, as people interact and share experiences, they may learn about their potential partner's needs, which may change their assumptions, and may eventually create a mutual platform of trust (Rose-Anderssen \& Allen, 2008). Due to the issue of risk, people may also substitute trust with control. Control as a trust substitute is characterized by formal, contractual control with an imposition of procedures for monitoring (Nooteboom, 2003). As a substitute for control, rational trust would be based on evidence of the partner's competence and intentions to conform.

In practice, rational trust becomes the criteria used for supplier selection. However, sustaining close relationships is a continuous effort of nurturing mutual expectations.

\section{The Dynamic Connection between Multiple Work Activities}

Supply chains as evolutionary networks of multiple work activities can be presented in its simplest form as the interaction between two companies in Figure 3 (see Engeström, 2001). Dilemma situations are experienced at boundaries between firms.

The object formation process in the diffuse boundary zone between Company $A$ and Company $B$ in Figure 3 is as follows. First, Objects A and B are the objects Company $A$ and Company $B$ respectively start off forming within each company. These are the visions or purposes each company is collectively developing for their role in the supply chain. Secondly, Objects A2 and B2 are the emerging objects the companies bring into the boundary zone of collaboration between them. Object $C$, therefore, is Company A's and Company B's collaborative understanding of their collective work activity. The difference between A2 and B2 makes the boundary zone, Object C, emerge.

The risk-sharing partnership can be characterized by a continuous object formation process in sometimes multiple and diffuse boundary zones. In this context, as Lektorsky (1984) argues, the object becomes clearer as people co-explore this boundary zone.

In the case results and discussion section, the evolutionary transformations of relationships in boundary zones are explored within the framework of Figure 1.

\section{Method of Data Collection}

This paper is a part outcome of a three-year research project on the evolution of commercial aerospace supply chains. Data was collected in two steps: a literature research and interviews. The research started off by conducting a literature research on: supply chains in general; on aerospace supply chains specifically; historical accounts of aircraft production; literature on evolution, learning, knowledge and change; and data from company internet sources. The treatment of data involved systematic coding of categories identified in the texts. It meant a process of continuous comparison and recoding of categories. The data was used to create an evolutionary classification scheme of commercial aerospace supply chains. It 
concluded the first phase of the project.

The second phase of the project was concerned with the perspectives of key players of one specific supply chain regarding the evolution of large aircraft supply chains. Therefore, based on the interpretation of the literature research data, an evolutionary form of semi-structured interview was chosen to obtain rich data. Richness of data would be less by questionnaire survey or structured interviews. Such instruments would produce data that was easier to compare but would be unlikely to have revealed things unfamiliar to the researcher. At the start of the interview sessions, the interviewees were presented with a list of issues identified from the secondary data: How is the evolution of your company's supply chains represented by changes of key supply chain practices and supply chain systems? How have key practices changed and been introduced along the life cycle of an aircraft model and from aircraft model to aircraft model? These issues were to be discussed in terms of the issues of: types of supplier selection, types of relationships with customers and suppliers, coordination and integration, training, learning and development, i.e., how do people learn and therefore change practices, quality assurance, risk, lean/agile, costs, offsets, technology and future scenarios. This paper focuses on the relationship issues elicited from the interviews.

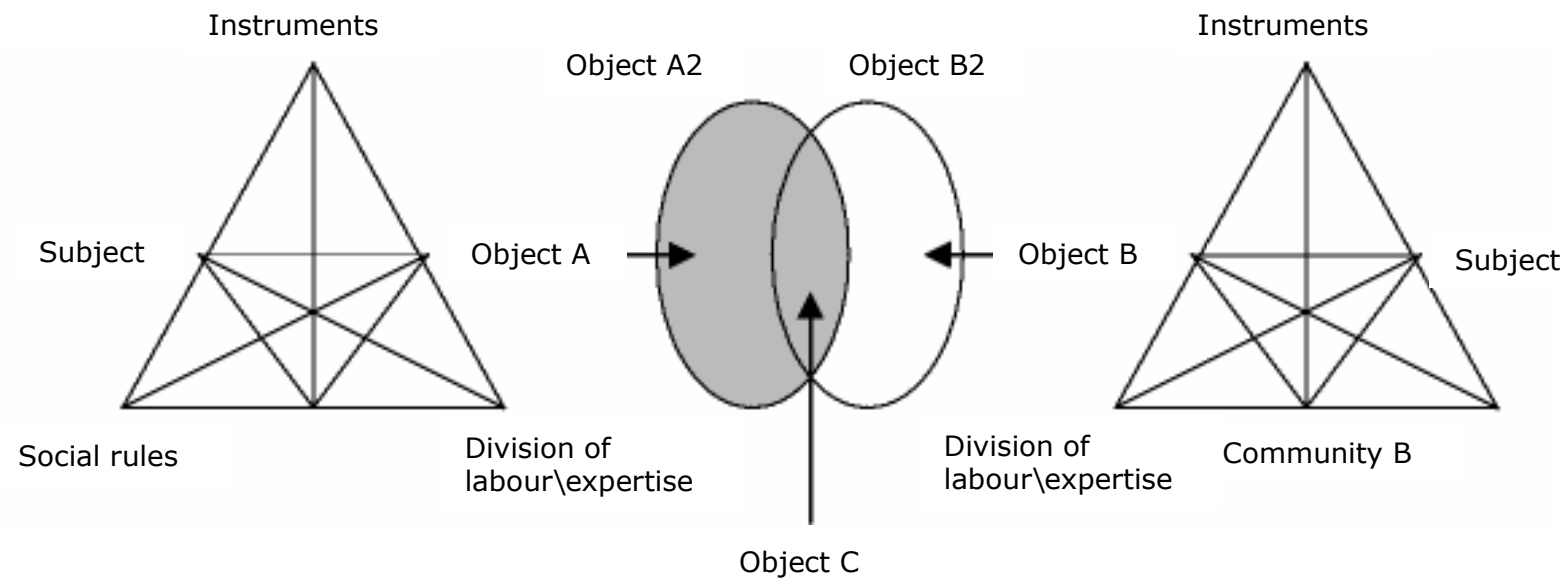

Figure 3. Interaction between Two Companies in a Supply Chain

Nineteen interviews took place in Europe, Japan and the USA at the levels of airframe manufacturer and first-tier suppliers in the second half of 2006. The interviews were conducted in seven companies with senior managers and directors in each company. Each session took from $1^{1 /} / 2$ hour to 2 hours. Every interview session was recorded on tape for later transcription. The interviews were conducted either as individual interviews or as focus group interviews. The first seven interviews took place as individual interviews. To enhance the richness of data, it was agreed with three companies in Japan and the USA to conduct focus group interviews within their companies. The idea was that each member of the focus group community would bring unique experiences and perspectives into the interview session.

In the focus group interviews conducted in this research, open-ended questioning took place within the framework of the semi- structured interview session. This occurred as interviewees would reflect on what others were saying and discuss that. In that sense, the interviews became interactive conversations. Again each of the interview sessions became a foundation for the sessions to follow. Although the interviewees were given the same semi-structured questions at the start of each session, an iterative practice took place in that the researcher would intervene in the conversation based on the data retrieved during previous 
interviews and also ask for elaboration on what was said in the present interview. In that sense, he became an active member of the focus group community.

The advantage of individual interviews over focus group interviews, however, is the control the interviewer has with closer communication with the interviewee (Morgan, 1997). Our experience, however, is that our interviews of focus groups became close conversations between the interviewees. This peer interaction helped expand on the issues to be explored. The interviewees collaborated in an activity where the object was to explore and make sense of specific issues. Therefore due to the interviewees' complementary insights, the synergies produced were an expansion of what the individuals could have produced alone. The atmosphere also became more relaxed than in the individual interviews where the individual would be under constant pressure to perform.

\section{Case Results and Discussions}

In the following sections, a developmental process of changing supply chain relationships is presented. The success of one supply chain form of highly collaborative relationships between airframe manufacturer, airlines and first-tier suppliers for one aircraft model is developed into risk-sharing partnerships for a new aircraft model.

\section{The Instrumentality of Relationships in Aerospace Supply Chains}

Identification of Competitive Advantage - Relationship Promotion

When the airframe manufacturer was losing market share, an initial dilemma occurred. They chose to involve more strongly the needs of airlines. This was the point of departure of the collaborative supply chain form.

A decade ago really, probably, [we] felt like it applied more to working together with our airline customers as a stronger connection. In driving the product design the airlines were embodied in the model $[x x x]$ plane, which has got a huge part of the market compared to the competition. (Airframe manufacturer, interviewee 1)

Bringing the customer into the activity of aircraft design increased the diversity of perspectives influencing an object for user-friendly aircraft design. The positive experience with close relationships to airlines also encouraged close relationships to be developed with suppliers. These relationships were used as instruments for bringing together latent expertise for producing more customer desirable aircraft.

And I think we have learned, we have been learning that aspect of collaboration applies in more than just as [with] the customer. So we have been moving in a direction to be more collaborative with our partners. Sharing more, earlier, involving them earlier and more deeply in our design. So that collectively we can achieve something better than the old producer system. (Airframe manufacturer, Interviewee 1)

The identification of a relationship form that potentially could facilitate innovation and competitive advantage was the point of departure of forming a new object (Object $A$ in Figure 3 ). Expanding on imagining the future happened through the entrepreneurial step where the airframe manufacturer brought selected suppliers into the boundary zone for developing a shared object (Object C in Figure 3)

Instruments for Initializing New Relationships - Power and Expert Promotion

The aircraft manufacturer was the company that had to face the airlines in the market directly. Thus their interpretation of market demand was essential for the 
success of the supply chain as a whole. And in that sense, the airframe manufacturer as a major customer of the suppliers was in a position of power to impose a reflection of the airlines' demand. Although the supply chain hierarchy had not changed at the initialization stage, a mutual need situation had been created. It was in the interests of both the airframe manufacturer and the suppliers to sustain their presence in the market.

Bringing the airlines and its suppliers into an object formation process of userfriendly design and adopting the practices used by competitors, gave the airframe manufacturer competitive ability with the plane xxx. But it did not give them competitive advantage as they had only made marginal improvements to existing airplane concepts. In other words, they were listening to market needs but they did not create and present something radically new to the market.

I think that was taking an existing plane and making point solutions. It was taking low risk and a conservative approach. We made improvements with the cockpit, the navigation system, the seating and storage. They were what I call point solutions integrated. (Airframe manufacturer, interviewee 2)

A more proactive response to the fiercer global competition was made when the airframe manufacturer considered a relationship form that could give them competitive advantage. Therefore to be able to move beyond the marginal improvements based on the imagination of the customer (Veryzer, 1998), they needed to cross boundaries into the unknown. This meant moving totally away from old concepts of aircraft design. The airframe manufacturer realized that this could not be resolved through their own actions alone (Kerosuo \& Engeström, 2003). Risk-sharing partnership was the relationship form that could connect the diverse capacity needed for radical change. The selection criteria were based on rational trust. This was built on long-term relationships, and upfront issues of financial and technological capabilities.

You almost have a different requirement of a supplier upfront capabilities. But those capabilities now quickly move into a sustaining load. They are a very different set of capabilities. The upfront capabilities

are characterized by financial and technological capacities. (Airframe manufacturer, interviewee 3)

Changing well-established relationships meant divorcing old routines and practices. The airframe manufacturer was in power to do so. Therefore change could be initiated by the airframe manufacturer withdrawing existing items such as long-term contracts and replacing them with new risk-sharing contracts.

And if you look at the main contracts, for example, for the [new airplane], they have called back the terms we have with them, pretty much straight through. And it is a partnership you know. They have become really a part of our business in the way their contract reflects. There is risk associated with that obviously. (European mechanical systems supplier, interviewee 1)

The power of expertise gave the selected supplier an advantage towards the airframe manufacturer. This contractual interdependency between the airframe manufacturer and supplier empowered the supplier as long as he complied with the contract. However, once contracts had been signed, the power of national airlines to demand use of suppliers from their own country was part of that complex system. This power exercise was balanced through the airframe manufacturer and risksharing partners' choice of suppliers in these countries to promote sales of planes and secure local maintenance for the aftermarket of equipment and systems. Thus the supply chain became a complex system of power relationships (Engeström, 2000). 
We essentially take into account market access. We take into account access to capital market, access to technology. (Airframe manufacturer, interviewee 3)

We also approached one country to develop engineering skills because we know that when we introduce commercial aircraft into a commercial market, those airlines would need engineers help them maintain those airplanes. We have network relationships and an infrastructure that supports those sales. (Airframe manufacturer, interviewee, 2)

We have global relationships with suppliers of the new aircraft model and these are different. These are actually risk-sharing partners. We ask them to take on the design, the certification and the fully integrated work for key elements of that aeroplane. (Airframe manufacturer, interviewee 4)

We need other companies to be risk-sharing partners that could be financially, but also be from a sales standpoint. So it also mitigates our risk investing billions of dollars on our own. We now have partners with us who help look at this.

(Airframe manufacturer, interviewee 2 )

Although the relationships evolved from a mutual need situation, the selection of partners was based on rational trust (Nooteboom, 2003). That is, the tier below had to show competence and intentions to conform to the impositions put upon them from above.

Only we are healthy enough to invest a huge amount of money for this project, and [have the] human resources, [and the] technical background. Those three factors. Our process itself is quite lean in its design. It was designed that way. (Japanese materials supplier, interviewee 1 )

We have invested [a] very huge [amount of] money to build our new facilities for the [new aircraft model]. [The airframe manufacturer] is applying lean [systems]. They are directing us to build under their instructions, [and] learning lean concepts. Our general manager and executive have changed their mind. We must be lean. So we are trying to be lean. Our suppliers stay in previous situation. First, we must learn, then we will teach them. (Japanese structural supplier, interviewee 1)

First-tier suppliers with a long history of compliance with the airframe manufacturer satisfied the initial criteria for rational trust.

Another one is [our] accumulated role of history with the airframe manufacturer [of] more than 10 years. So this activity, the reliability of us has been increased. This is quite [an] important factor [for] why we are selected. (Japanese materials supplier, interviewee 1 )

Conclusively, a complex system of interacting instruments was used for initializing new relationships. First, the airframe manufacturer used the mutual need situation as an instrument for proposing change. Simultaneously, the key suppliers could use the rational trust they had built up with the airframe manufacturer as an instrument whereby they would be selected as risk-sharing partners. Second, the airframe manufacturer used their power as an instrument to change contracts. Simultaneously, the key suppliers used their power of unique expertise, financial resources and access to their local markets to negotiate their position in the supply chain.

Instruments for Developing Close Relationships - Process Promotion

The interviewees realized that it is beneficial to develop relationships based on more trust and transparency. One approach that could potentially develop into mutual 
expectations and into long-term relationships occurred when a supplier was encouraged to develop their products for their own future benefits. The supplier thereby became more innovative at the same time as the customer received more innovative systems and units of systems. By developing their expertise these lower tier suppliers changed their relationships by becoming suppliers of whole units. In these hierarchical regimes, first-tier suppliers actually empowered low cost economy (LCE) suppliers to become more trusted by letting them make simple parts first; thereby letting them gradually learn, develop competence and thus develop closer relationships to their customer. However, creative initiatives are not advantageous for an aircraft model if they are not introduced based on mutual expectations. These mutual expectations must come about through a collective object formation process on what kinds of innovations fit airline demands at the same time as they fit the production systems of the aircraft model.

To develop relationships takes a lot of that informal conversation in trust and creditability through your words. (Airframe manufacturer, interviewee 2 )

And developing a relationship we try to get more trust in that relationship and more transparency in that relationship. Relationships are a very cyclic thing. Partly because we haven't got clear commodity strategies, we tend to be very dependent on the chemistry between CEO of a suppliers and the appropriate senior person inhouse. I think the relationship side of it and supplier selection is really based on who you know. (Engine supplier, interviewee 1)

If we identify something we want to work at together with a supplier then we will have an Early Suppliers Engagement contract. And that contract clarifies who owns the intellectual property. And we use that value of the IP as part of the benefit of working with the suppliers. [It] gives them the opportunity to exploit that technology. (Engine supplier, interviewee 2)

We give the LCE suppliers a development plan. Start them [off] with fairly simple stuff. You are building the relationship on maybe some machine part, and then you start to step up to complete design and manufacture of an actuator or an entire gearbox or something like that. (European mechanical systems supplier, interviewee 2)

So we have a supplier that comes up with a really good idea. But our customer says: we are not going to accept that. They want a stable thing. Also when a supplier comes up with a new idea and technology, getting it on an existing programme is very difficult in terms of incorporation. We are learning that we have to get better co-ordination on where they are spending their R\&D money. (Airframe manufacturer, interviewee 3)

Triangular relationships between a first-tier supplier, western prototype suppliers and LCE mass producers of a unit illustrate a collective approach to a global production dilemma situation.

As far as supplier relationships are concerned, we are trying to involve some of our traditional suppliers in co-operative arrangements with [suppliers in] low cost economies. So that means, the machined [parts] suppliers would be involved at the prototyping stage. The parts in the volume production phase may be offloaded to a low cost country area. (Electrical systems supplier, interviewee 1 )

Developing supply chain relationships, as the case shows, is not a straightforward process of implementation. Despite the point of departure, there is an intention to collaborate. Beyond the point of the contract agreement, the developmental process relies on very individual interactions in the boundary zone 
(Figure 3) between the companies.

Distinct cultural boundaries create another dilemma in yet another diffuse boundary zone (Figure 3 ) between companies in the supply chain. Although the situation is between risk- sharing partners, this is most typically exemplified by the difference between Japanese and American practices (Cristiano et al., 2000). The Japanese individual assumes collective obedience to the system and the level above, and therefore assumes power difference and distance to strangers. On contrast, the American individual would relate to a more individualistic regime of low power difference and small distance to strangers and more freedom of action for the individual.

You literally have to watch the Japanese all the way to get them to [perform], handholding, walking through [the process at] every level of their organization to get them to go at the risk level and speed we need to go ahead. (Airframe manufacturer, interviewee 5)

The boundary zone therefore becomes even more diffuse when one partner company has to guide another partner due to different cultural performance expectations. These problems are therefore not specific to risk-sharing partnerships, but are due to mismatch of collaborative skills across cultural boundaries.

However, collaboration across company interfaces is not only a challenge between Asian and Western companies. As the case shows, integrating the global network of airplane structure risk-sharing partners also needs substantial developmental attention.

The airplane structures suppliers are difficult to integrate. The co-ordination and integration is maybe one of the keys to successful companies. We see ourselves as large-scale integrators. (Airframe manufacturer, interviewee 5)

As the risk-sharing relationships' intended collective practices are not fully implemented, it means that the airframe manufacturer as a large-scale integrator still has to make impositions on suppliers. Thus in line with Cox's (2004) argument, the interdependence between risk-sharing partners and the dominance by the airframe manufacturer is necessary for the development of these suppliers and for making the supply chain effective.

Top-down or bottom-up innovations are realities in any kind of customer/supplier relationship. However, neither encourages collaboration as mutual expectations are not met. Whether it is in relationships between risk-sharing partners or between different tiers in the supply chain, identifying something together takes place in a boundary zone of mutual expectations. This collective object formation for identifying the 'new' together can thus be made to fit the process of production as well as customer needs. The main thing is that those affected by constructing something new are involved in decision-making processes. Although risk-sharing partnerships are supposed to enhance innovation through bringing together a diversity of expertise and the financial resources to invest in exploration and innovative solutions, in this case these relationships are still at a developmental stage. It seems that different and established company routines of fixed behaviour (Allen, 2001) are inhibiting the ability to learn outside existing boundaries and thereby to participate in an object formation across company boundaries.

\section{Instruments for Sustaining Close Relationships and Innovation}

As important as it was to destroy obsolete artefacts, it was important to establish new enduring artefacts to support new forms of relationships. The question will therefore always be whether new enduring artefacts such as contracts, e-portals, design and engineering structure adjustment programmes and product planning 
tools can be effectively used across company interfaces not only at present but also are flexible enough for the supply chain to sustain into the future.

[For] the integration of communication and data transfer, we have developed portals in our systems of design and engineering that enable us to work with our suppliers and researchers and partners at a completely virtual basis. (Airframe manufacturer, interviewee 4)

Sustaining close supply chain relationships requires effort beyond establishing enduring artefacts. Compared to sustaining relationships within a single firm, sustaining relationships between firms is more complex. This is because the distance and power issues may be more pronounced in a supply chain than within an individual firm. First, people are separated physically by interacting from different localities, making it more difficult to build up the trust that naturally evolves between people in daily face-to-face contact. Second, there is an inherent power present in customer/supplier relationships. The risk- sharing partnership, however, invites at least a decrease in power difference between partners due to the strong interdependence the unique diverse expertise held by each partner gives. Therefore to take advantage of this diversity, it is realized that face-to-face and other more direct personal interaction across company boundaries are paramount for nurturing relationships. Multi-voicedness is represented through personal relationships. These serve as nodes between firms, and echoes Engelstad and Gustavsen's (1993, p. 244) findings. They claim that the network can be seen as consisting not of the participating organizations but of groups of actors linked to each other where the groups operate according to the principle of a democratic dialogue internally as well as in relation to each other.

Today it is much more of an open communication, working together, and [with] continuous improvement. The sustaining part is characterized by close relationships and collaboration. (Airframe manufacturer, interviewee 5)

Things like schedules, purchase orders, the transactional parts of the relationship happen via e-portals through [the] internet now with all our suppliers. It is an excellent system. Suppliers like it and it works very well. What we lost was the interaction between people. But we now have material controllers who own relationships with suppliers. And they know the person, and that relationship is better. (Electrical systems supplier, interviewee 2)

The types of relationships with customers and suppliers tend to be very individual kind of responses. It depends upon the company you have relationships with, and what their philosophy is. (Japanese materials supplier interviewee 2)

In this case, practising development and sustainability of the risk-sharing partnerships are done in the context of a new aircraft model development. This context changes due to the disturbances between the connected activities (Rose-Anderssen et al., 2005). As the case shows, these disturbances come about as there are imperfect actions promoting corrective actions in a dynamic context of transformation. Although the relationships are immature, the collective investment in unique expertise and financial resources are producing very promising outcomes in terms of a conceptually new aircraft. Thus, even if the boundary zone between firms regarding details may sometimes be diffuse, due to the open space for negotiations and peer guidance the risk- sharing partnership gives, successful innovation is achieved.

Throughout the world, our new airplane is recognized as an extraordinarily high technology advanced aircraft. People believed that we have stepped out a very innovative solution. We have stretched the boundaries of technology, offered a unique solution that has never been offered to the industry before. We are an 
extremely risk aversive company. And I think this is an indication we have started to accept risk and be innovative. Quite honestly we have to be global. We have those relationships. So globally, I think those relationships are really important. (Airframe manufacturer, interviewee 2)

So we go into production of [the new airplane] around, well it starts next year. And it wraps up quite quickly because they have been very successful [with that] aircraft. (European mechanical systems supplier, interviewee 2)

In conclusion, shared ownership to building an aircraft, multi-voicedness and successful innovation of new aircraft became instruments for sustaining relationships. A successful outcome in terms of an innovative product can be argued to be the strongest ingredient for nurturing risk-sharing partnerships. And this helps develop the relationship further.

\section{Risk-Sharing Partnerships as Instruments for Innovation}

The model of the instrumentality of relationships (Figure 1) has been used to mould the text in these subsections into an interactive model of supply chain relationship evolution. This complex evolutionary model confirms risk-sharing partnerships as strong instruments for innovation (Figure 4).

The aim of risk-sharing partnerships is to go beyond simple technology transfer. It is about knowledge and technology transformation as a collective process for creating entirely new concepts of aircraft technology. As such, it is interesting as it expands the capacities to go beyond present capabilities to achieve competitive advantage in the global space. The collective investment into this expansion is what risk-sharing is about.

Western suppliers as well as their global competitors were initially invited to present their up-front capabilities to engage in risk- sharing partnerships. Sadly, many Western suppliers are not prepared to do that.

We need to find suppliers who can grow and develop, and contribute to the innovation process. I think, by and large, most Western suppliers have not woken up to this reality. They can't develop. They can't be our suppliers as we need to go forward. (European mechanical systems supplier, interviewee 2)

That meaning we need to take more of a risk letting them get on with it. The question is; there are not many suppliers that are big enough to carry on a mass project development. (Engine supplier, interviewee 2)

However, risk-sharing partnerships are open and transparent relationships for the sharing of experiences. Knowledge created by partners during the processes of aircraft development is shared. They are therefore gaining knowledge they would not necessarily have developed alone. To enhance competitive advantage, the airframe manufacturer invites the best expertise available from the global space into risk-sharing partnerships. Innovation is therefore not out- sourced or transferred; it is created within the risk-sharing partnership. Although knowledge is shared, early supplier engagement contracts may protect intellectual property rights.

Changing practices to support risk-sharing partnerships is a major step in the evolution of commercial aerospace supply chains. Risk- sharing partnerships facilitate going beyond the limitations of incremental innovation. It is about the collective approach to airplane technology transformation. Advances in new concepts in aircraft design based on advances in material technology help facilitate that. Pritchard and MacPherson's $(2004,2007)$ concern about substantial technology transfer from US 


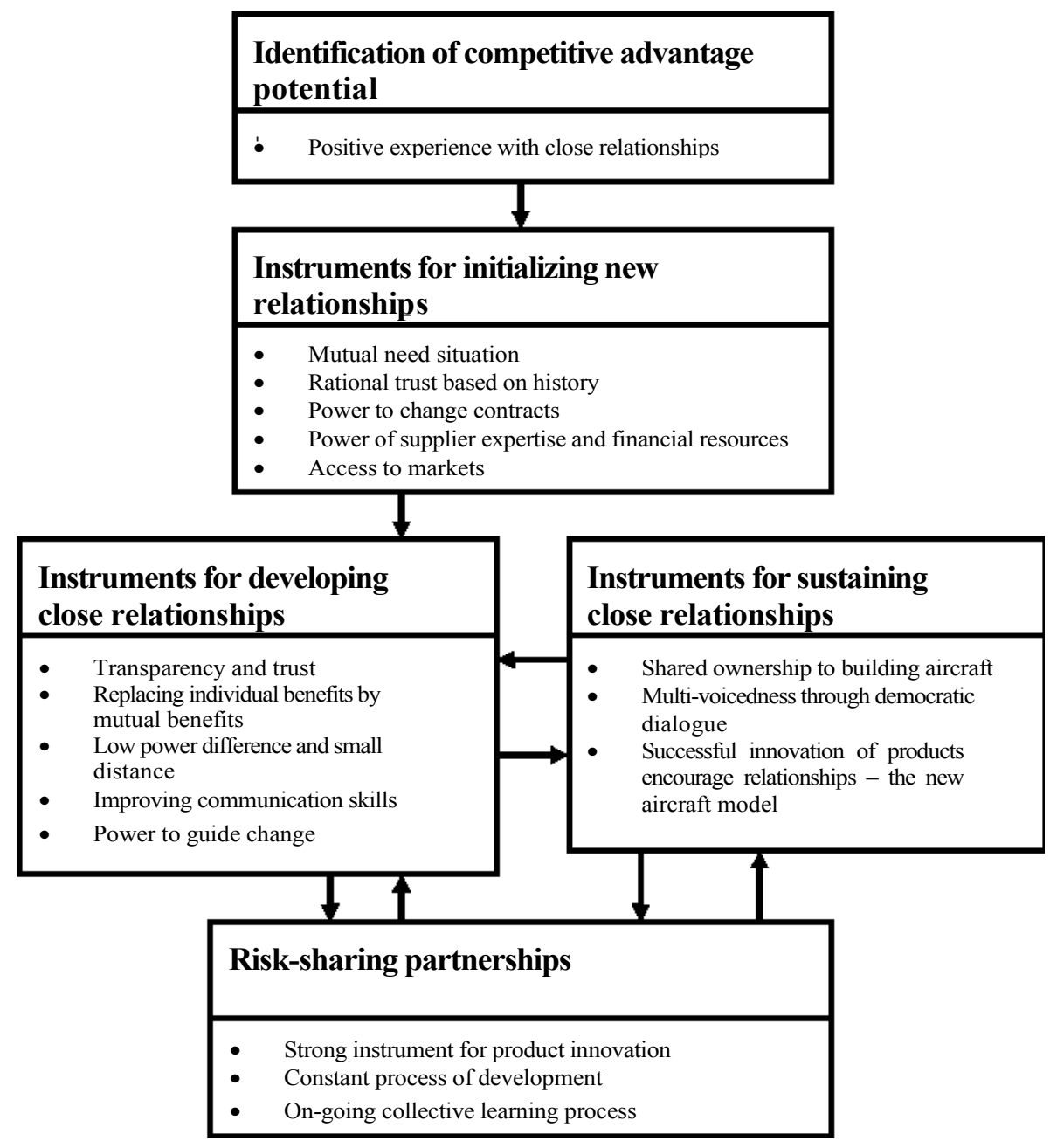

prime contractors to non-Western companies, thus, does not hold. Western companies need to evolve with the ever-changing global market realities to be considered as risk- sharing partners to survive.

Risk-sharing partnerships have in this case shown to be a strong instrument for the creation of a complete innovative solution for a new aircraft model. The new aircraft represents a totally new aircraft concept whilst its predecessor was based on innovations to various part of an existing aircraft type.

The risk-sharing partnership has been shown to facilitate diversity of expertise. The power of expertise by suppliers is a move away from the tradition of one dominant voice towards the multi-voiced approach of this activity network. The combination of financial strength and expertise held by each partner brought together by their codeveloped object has facilitated exploration and learning with the outcome radical innovations. Although some actions in the case were characterized as imperfect, the strength of the risk-sharing partnership is that it brings expert firms into an initially diffuse boundary zone where they can co-develop a shared object (Figure 3). It is this facilitation of strong interdependence between partners that is the strength of risksharing partnerships compared to more loosely collaborative or single-voiced dominated supply chain forms. 


\section{Concluding Remarks: Theoretical and Practical Implications}

The paper set out to explore the effect of risk-sharing partnership on innovation and competitive advantage in the market for large commercial aircraft. This was done using an evolutionary model of the transformation of relationship practices. Within the framework of the model, a case of one supply chain was analysed using a combination of activity theory and complex systems thinking.

Through the perspectives of activity theory and complex systems thinking, the transformation of a supply chain relationship form from the level of collaborative practices to the collective practices of risk-sharing partnerships was discussed. It is the strong collective effort by the risk-sharing partners to develop common objects for their shared activities that connects and develops the diversity of expertise and opinions into a dynamic process that could otherwise have led to pulling the supply chain in multiple directions. Since this supply chain is still immature in terms of object comprehension for some parts, guidance is needed to make the object clearer. Kratzer et al.'s (2006) argument that creative performance and innovation can be positively affected by a diversity of influences is supported by this paper. In previous collaborative supply chain relationships, the airframe manufacturer took most of the risk associated with innovation, development and production (Williams et al., 2002). This domination by the airframe manufacturer is in this case gradually transformed into a more multi-voiced relationship of diverse company capabilities. The expert partners are given the responsibility to develop their high technology products within the context of the common object. This is neither top-down nor bottom-up innovation but an individual contribution in a collective setting.

The case discussed in this paper indicates the synergetic effects of bringing together a diversity of high technology expert companies to produce radical innovation.

Implementing global risk-sharing partnerships is a complex developmental process as they have to be adapted across different cultural boundaries. The practical learning is therefore that there are no standard solutions to the implementation processes. They are subject to trial and error in diffuse boundary zones of collective object formation processes of trust-building and mutual expectation development.

\section{References}

Allen, P.M. (2001a) A Complex Systems Approach to Learning in Adaptive Networks. International Journal of Innovation Management, 5, 149-80.

Allen, P.M. (2001b) Knowledge, Ignorance and the Evolution of Complex Systems. In Foster, J. and Metcalf, S. (eds.), Frontier of Evolutionary Economics: Competition, Self-Organization and Innovative Policy. Edward Elgar, Cheltenham.

Bachmann, R. (2003) Trust and Power as Means of Coordinating the Internal Relations of the Organization: A Conceptual Framework. In Nooteboom, B. and Six, F. (eds.), The Trust Process in Organizations - Empirical Studies of the Determinants and the Process of Trust Development. Edward Elgar, Cheltenham.

Blackler, F. (1993) Knowledge and the Theory of Organizations: Organizations as Activity Systems and the Reframing of Management Studies. Journal of Management Studies, 30, 863-84.

Blackler, F. (1995) Knowledge, Knowledge Work and Organizations: An Overview and Interpretation. Organization Studies, 16, 1021-46.

Burns, T.R. and Flam, H. (1987) The Shaping of Social Organization - Social Rule System Theory with Applications. Sage Publications, London.

Cagliano, R., Caniato, F. and Spina, G. (2004) Lean, Agile and Traditional Supply; How Do They Impact Manufacturing Performance? Journal of Purchasing and 
Supply Management, 10, 151-64.

Cox, A. (2004) The Art of the Possible: Relationship Management in Power Regimes and Supply Chains. Supply Chain Management: An International Journal, 9, 34656.

Cristiano, J.J., Liker, J.K. and White, C.C. III (2000) Customer-Driven Product Development through Quality Function Deployment in the U.S. and Japan. Journal of Product Innovation Management, 17, 286-308.

Engelstad, P.M. and Gustavsen, B. (1993) Swedish Network Development for Implementing National Work Reform Strategy. Human Relations, 46, 219-48.

Engeström, Y. (1987) Learning by Expanding: An Activity-Theoretical Approach to Developmental Research. Orienta-Konsultit, Helsinki.

Engeström, Y. (2000) Comment on Blackler et al. Activity Theory and Social Construction of Knowledge: A Story of Four Umpires. Organization, 7, 301-10.

Engeström, Y. (2001) Expansive Learning at Work: Toward an Activity Theoretical Reconceptualization. Journal of Education and Work, 14, 133-56.

Esposito, E. (2004) Strategic Alliances and Internationalisation in the Aircraft Manufacturing Industry. Technical Forecasting and Social Change, 71, 443-68.

Foot, K. (2002) Pursuing an Evolving Object: A Case Study in Object Formation and Identification. Mind, Culture and Activity, 9, 132-49.

Foucault, M. (1972) The Archaeology of Knowledge. Harper \& Row, New York.

Foucault, M. (1980) Power/Knowledge, Selected Interviews, and Other Writings, 19721977. Harvester Wheatsheaf, Hemel Hempstead.

Gemünden, H.G., Salomo, S. and Hölze, K. (2007) Role Models for Radical Innovations in Times of Open Innovation. Creativity and Innovation Management, $16,1-19$.

Giddens, A. (1982) Power, the Dialectic of Control and Class Structuration. Cambridge University Press, Cambridge.

Goffin, K., Lemke, F. and Szwejczewski, M. (2006) An Exploratory Study of 'Close' Supplier- Manufacturer Relationships. Journal of Operations Management, 24, 189209.

Hasu, M. and Engeström, Y. (2000) Measurement in Action: An Activity-Theoretical Perspective on Producer-User Interaction. International Journal of Human-Computer Studies, 53, 61-89.

John-Steiner, V. (2000) Creative Collaboration. Oxford University Press, Oxford.

Kerosuo, H. and Engeström, Y. (2003) Boundary Crossing and Learning in Creation of New Work Practice. Journal of Workplace Learning, 15, 345- 51.

Kratzer, J., Leenders, R.Th.A.J. and van Engelen, J.M.L. (2006) Team Polarity and Creative Performance in Innovation Teams. Creativity and Innovation Management, 15, 96-104.

Lefebvre, E. and Lefebvre, L.A. (1998) Global Strategic Benchmarking, Critical Capabilities and Performance of Aerospace Subcontractors. Technovation, 18, 22334.

Lektorsky, V.A. (1984) The Dialectic of Subject and Object and Some Problems of the Methodology of Science. Progress Publishers, Moscow.

McCarthy, I.P. (2004) Manufacturing Strategy: Understanding the Fitness Landscape. International Journal of Operations and Production Management, 24, 124-50. 
Miettinen, R. and Virkunnen, J. (2005) Epistemic Objects, Artefacts and Organizational Change. Organization, 12, 437-56.

Morgan, D.L. (1997) Focus Groups as Qualitative Research, Qualitative Research Method Series, Vol. 16. Sage Publications, Thousand Oaks, CA.

Nooteboom, B. (2003) The Trust Process. In Nooteboom, B. and Six, F. (eds.), The Trust Process in Organizations - Empirical Studies of the Determinants and the Process of Trust Development. Edward Elgar, Cheltenham.

Nooteboom, B. and Six, F. (2003) Introduction. In Nooteboom, B. and Six, F. (eds.), The Trust Process in Organizations - Empirical Studies of the Determinants and the Process of Trust Development. Edward Elgar, Cheltenham.

Pritchard, D. and MacPherson, A. (2004) Outsourcing US Commercial Aircraft Technology and Innovation: Implications for the Industry's Long Term Design and Building Capability. Canada-United States Trade Center, Department of Geography, State University of New York.

Pritchard, D. and MacPherson, A. (2007) Strategic Destruction of the Western Commercial Aircraft Sector: Implications of Systems Integration and International Risk-Sharing Business Models. Aeronautical Journal, 111, 327- 34.

Romano, P. (2003) Co-ordination and Integration Mechanics to Manage Logistic Processes across Supply Networks. Journal of purchasing and supply Management, 9, 119-34.

Rose-Anderssen, C. and Allen, P.M. (2008) Diversity and Learning for Innovation: Dialogue for Collaboration. Journal ofManagement Development, 27,307-27.

Rose-Anderssen, C., Allen, P.M., Tsinopolous, C. and McCarthy, I. (2005) Innovation in Manufacturing as an Evolutionary Complex System. Technovation, $25,1093-105$.

Rose-Anderssen, C., Baldwin, J.S., Ridgway, K., Allen, P.M., Varga, L. and Strathern, M. (2009) A Cladistic Classification of Commercial Aerospace Supply Chain Evolution. Journal of Manufacturing Technology Management, 20 (forthcoming).

Samaranayake, P. (2005) A Conceptual Framework for Supply Chain Management: A Structural Integration. Supply Chain Management: An International Journal, 10, 47-59.

Scollon, R. and Scollon, S.B.K. (1983) Narrative, Literacy and Face in Interethnic Communication, Ablex Publishing Corporation, New York.

Veryzer, R.W. (1998) Discontinuous Innovation and the New Product Development Process. Journal of Product Innovation Management, 15,304- 21.

Vygotsky, L.S. (1978) Mind in Society - The Development of Higher Psychological Processes. Harvard University Press, Cambridge, MA.

Williams, T., Maul, R.S. and Ellis, B. (2002) Demand Chain Management Theory: Constraints and Development from Global Aerospace Supply Webs. Journal of Operations Management, 20, 691- 706.

Womack, J.P., Jones, D.T., Roos, D. and Carpenter, D. (1990) The Machine that Changed the World - The Story of Lean Production. Rawson Associates, New York.

C. Rose-Anderssen (c.rose-anderssen@ sheffield.ac.uk) is a Research Associate at the Advanced Manufacturing Research Centre with Boeing, University of Sheffield. He is currently engaged in the ESRC research project 'Modelling the Evolution of the Aerospace Supply Chain'. He previously worked as a Research Officer in the project 'New Product Development as a Complex System of Decisions' at the Complex Systems Research Centre, Cranfield University. He worked as a naval architect and manager in the shipbuilding industry in Northern Europe for many years. He worked as a consultant in shipbuilding in Asia and as a manager in the Norwegian offshore engineering industry. 
Dr J.S. Baldwin is a Lecturer at the School of Management, University of Sheffield. He is currently engaged in the ESRC research project 'Modelling the Evolution of the Aerospace Supply Chain'. He has previously conducted research into the sustainability of complex systems with an emphasis on manufacturing in South Yorkshire. He is also involved in research on the evolutionary classification and modelling of industrial ecosystems.

Professor K. Ridgway, OBE, is head of the research institute, Advanced Manufacturing Research Centre with Boeing, University of Sheffield. He established the AMRC to carry out research in manufacturing technologies directly related to the aerospace industry. He previously held the position of Professor of Design and Manufacturing and was Director of the Ibberson Technology Transfer Centre, Department of Mechanical Engineering, University of Sheffield. He was awarded the OBE in 2005 for services to UK manufacturing industries.

Professor P.M. Allen is head of the Complex Systems Research Centre, School of Management, Cranfield University. He worked for 20 years with the Nobel Laureate, Ilya Prigogine in Brussels. For almost 30 years he has been working on the mathematical modelling of change and innovation in social, economic, financial and ecological systems, and the development of integrated systems models linking the physical, ecological and socio-economic aspects of complex systems as a basis for improved decision support systems.

L. Varga is a Research Officer at the Complex Systems Research Centre, School of Management, Cranfield University. She is currently engaged in the ESRC research project 'Modelling the Evolution of the Aerospace Supply Chain'. She works part-time for the Society of Information Technology. She also provides management consultancy and programme management to a number of public sector organizations. 